\title{
Pre-radiation enhances the cytotoxicity of docetaxel in head and neck squamous cell carcinoma cells
}

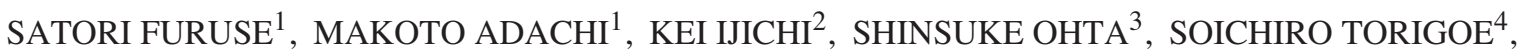 \\ MASATOSHI NAKAZAWA ${ }^{5}$, SATOSHI MIURA ${ }^{6}$, KENJI MITSUDO ${ }^{1}$ and IWAI TOHNAI ${ }^{1}$ \\ ${ }^{1}$ Department of Oral and Maxillofacial Surgery, Yokohama City University Graduate School of Medicine, Yokohama \\ 236-0004; ${ }^{2}$ Department of Otolaryngology-Head and Neck Surgery, Nagoya City University Graduate School of \\ Medical Sciences, Nagoya 467-8601; ${ }^{3}$ Department of Oral Surgery and Dentistry, Yokohama Sakae Kyosai \\ Hospital, Yokohama 247-8581; ${ }^{4}$ Department of Radiology, Yokohama Stroke and Brain Center, Yokohama \\ 235-0012; ${ }^{5}$ Department of Laboratory Animal Science and ${ }^{6}$ Radioisotope Research Center, \\ Yokohama City University School of Medicine, Yokohama 236-0004, Japan
}

Received November 20, 2009; Accepted January 11, 2010

DOI: $10.3892 /$ or_00000769

\begin{abstract}
This study was designed to determine the effect of the treatment schedule on the interaction between docetaxel and irradiation. Human head and neck squamous cell carcinoma (HNSCC) cells with different p53 status, and HSC4 (p53 wild-type) and CAL27 (p53 mutant type) cells were treated with docetaxel and irradiation using three schedules: i) concurrent treatment, ii) docetaxel pretreatment and iii) pre-radiation. Docetaxel and radiation inhibited the proliferation of HSC4 and CAL27 cells in a dose-dependent manner. However, irradiation pretreatment was more effective than the other treatment regimens in all cells. Our data suggest that pre-radiation in HNSCC cells significantly enhances docetaxel cytotoxity by arresting S-phase, and this provides the most effective treatment sequence of docetaxel and radiation combination therapy. Therefore, radiation followed by docetaxel may be the most effective sequence for head and neck cancer therapy.
\end{abstract}

\section{Introduction}

Head and neck squamous cell carcinoma (HNSCC) is a major health problem. Much of the recent progress has been made in locoregionally advanced inoperable disease, mainly in investigating the optimal combination of concurrent chemoradiotherapy and the introduction of new active drugs, such as docetaxel, in the induction phase of treatment. The

Correspondence to: Dr Makoto Adachi, Department of Oral and Maxillofacial Surgery, Yokohama City University Graduate School of Medicine, 3-9 Fukuura, Kanazawa-ku, Yokohama Kanagawa 236-0004, Japan

E-mail: amakoto@yokohama-cu.ac.jp; madachi_dds_phd@yahoo.co.jp

Key words: head and neck squamous cell carcinoma, docetaxel, radiation, combination therapy, cell cycle combination of docetaxel, cisplatin, and 5-fluorouracil (TPF) is now acknowledged as being the gold standard of induction treatment (1).

Docetaxel is a second-generation taxane, a semisynthetic derivative of paclitaxel originally derived from the yew tree, which inhibits certain tumor types in vivo and in vitro. The chemotherapeutic mechanisms of docetaxel are not yet fully understood, but available data show that this agent appears to promote microtubule bundle production and stabilizes tubulin polymer formation with consequent block of G2/Mphase of the cell cycle, followed by apoptosis of mitotically arrested cells or permanent mitotic block (2).

Combination therapy of docetaxel and radiation is a common procedure in the treatment of cancer to achieve an additive or synergistic effect and to reduce toxicity to the patient (3). The promising clinical activity of docetaxel has promoted considerable interest in combined treatment. In the past, studies of the interaction of radiation with docetaxel indicated that increased radiosensitivity occurred at the time of G2/M block. Mitotic arrest and apoptosis have been considered to be the dominant events leading to the radiosensitizing effect of docetaxel (4). In similar studies it was suggested that a taxane alone produced G2/M arrest and induced more pronounced cell killing (5). However, contradictory data suggest that the presence of $\mathrm{G} 2 / \mathrm{M}$ arrest did not appear to be sufficient to enhance radiation sensitivity (6).

Therefore, the aim of the present study was to determine whether the simultaneous and sequential administration of docetaxel and radiation has synergistic or antagonistic cytotoxic activity in HNSCC cell lines.

\section{Materials and methods}

Cells and cell culture. We used the HNSCC cell lines HSC4 and CAL27. HSC4 (p53 wild-type) cells were obtained from the Cell Resource Center for Biomedical Research Institute of Department, Aging and Center, Tohoku University (7). CAL27 (p53 mutant) cells were obtained from American Type Culture Collection (Global Bioresource Center ${ }^{\mathrm{TM}}$, VA, 

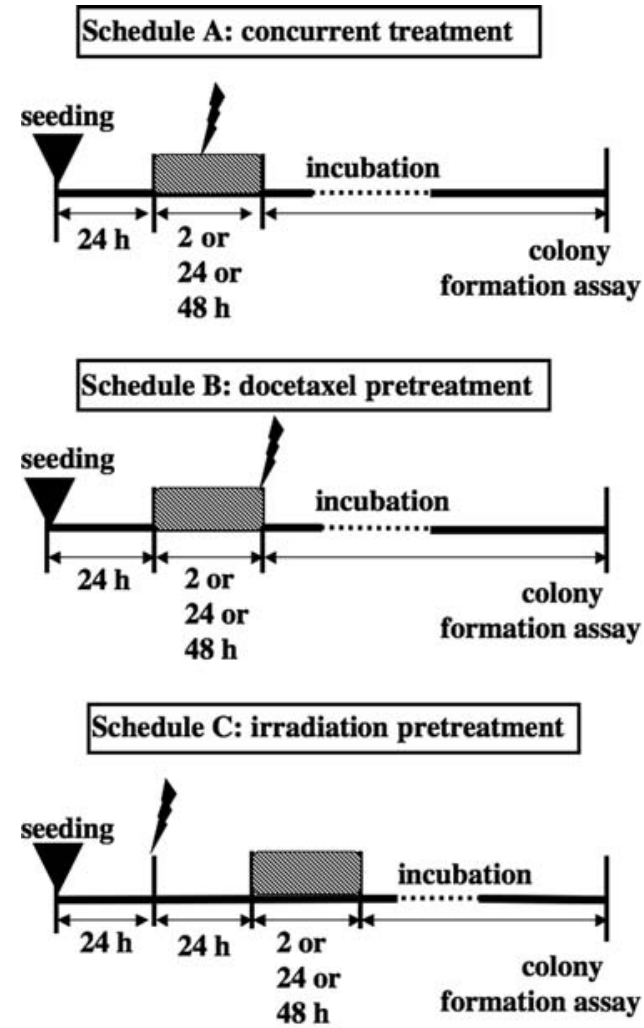

firradiation :docetaxel

Figure 1. Schematic diagram of the three protocols for treatment with a combination of irradiation and docetaxel. Irradiation, $3 \mathrm{~Gy}$; docetaxel, $10 \mathrm{ng} / \mathrm{ml}$ for $2 \mathrm{~h}, 0.5 \mathrm{ng} / \mathrm{ml}$ for 24 or $48 \mathrm{~h}$.

USA) (8). Both cell lines were maintained in Dulbecco's modified Eagle's medium (DMEM, Wako, Osaka, Japan) supplemented with $10 \%$ fetal bovine serum (FBS, Invitrogen, $\mathrm{CA}$, USA) in a humidified atmosphere of $5 \% \mathrm{CO}_{2}$ at $37^{\circ} \mathrm{C}$.

Docetaxel treatment and irradiation. Docetaxel (Taxotere ${ }^{\circledR}$, Sanofi-Aventis, Paris, France) was diluted in sterile dimethyl sulfoxide to a stock concentration of $1 \mathrm{mg} / \mathrm{ml}$. Working concentrations were diluted in DMEM and prepared fresh from the frozen stock solution just before use. Escalating doses from 0.5 to $50 \mathrm{ng} / \mathrm{ml}$ were used for each cell line. Docetaxel was removed by two washes with phosphatebuffered saline (PBS) $\gamma$-irradiation of cells with or without concomitant drug exposure was performed, using a ${ }^{137} \mathrm{Cs}$ irradiator (Gammcell 40 Atomic Energy of Canada LimitedRadiochemical Company, Ontario, Canada) at a dose of $0.816 \mathrm{~Gy} / \mathrm{min}$, up to $10 \mathrm{~Gy}$. Combination treatment was performed with three schedules as shown in Fig. 1. Cells were plated onto $6-\mathrm{cm}$ dishes from $1.0 \times 10^{2}$ to $1.0 \times 10^{4} / \mathrm{dish}$. After $24 \mathrm{~h}$, cells were exposed to docetaxel for 2, 24 or $48 \mathrm{~h}$ and concurrent irradiation (schedule A: concurrent treatment) or docetaxel exposure for 2, 24 or $48 \mathrm{~h}$ before irradiation (schedule B: docetaxel pretreatment), or irradiation before docetaxel treatment for 2, 24 or $48 \mathrm{~h}$ (schedule $\mathrm{C}$ : radiation pretreatment).

Colony formation assay for docetaxel and radiation sensitivity. The appropriate number of cells was inoculated into a 6-cm
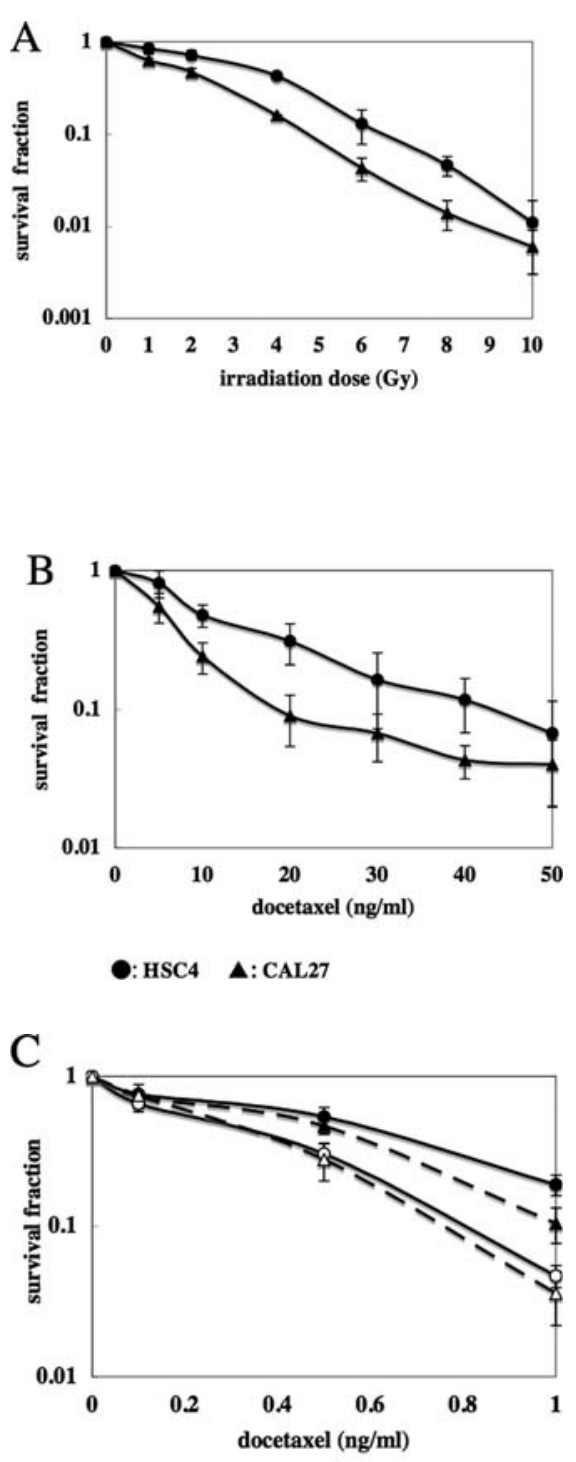

Figure 2. (A) Sensitivity of the HSC4 and CAL27 cells treated with irradiation. Dose-dependent effect of irradiation on survival in both cell lines. Each data point is the mean of three independent experiments. Vertical bars show standard deviations. (B) Sensitivity of the HSC4 and CAL27 cells treated with docetaxel for $2 \mathrm{~h}$. Dose-dependent effect of docetaxel on survival in both cell lines. Each data point is the mean of three independent experiments. Vertical bars show standard deviations. (C) Sensitivity of the HSC4 and CAL27 cells treated with docetaxel for 24 and $48 \mathrm{~h}$. Dosedependent effect of docetaxel on survival in both cell lines. Each data point is the mean of three independent experiments. Vertical bars show standard deviations.

dish, treated with docetaxel for 2, 24 and $48 \mathrm{~h}$ and irradiated. The cells were washed twice with PBS and the culture medium was exchanged for fresh medium after exposure to docetaxel. After 14 days, colonies were stained with $0.05 \%$ crystal violet. Colonies of 50 cells or more were scored as originating from a single clonogenic cell.

Cell cycle analysis using flow cytometry. Cell cycle distribution of both cell lines after docetaxel treatment or irradiation 

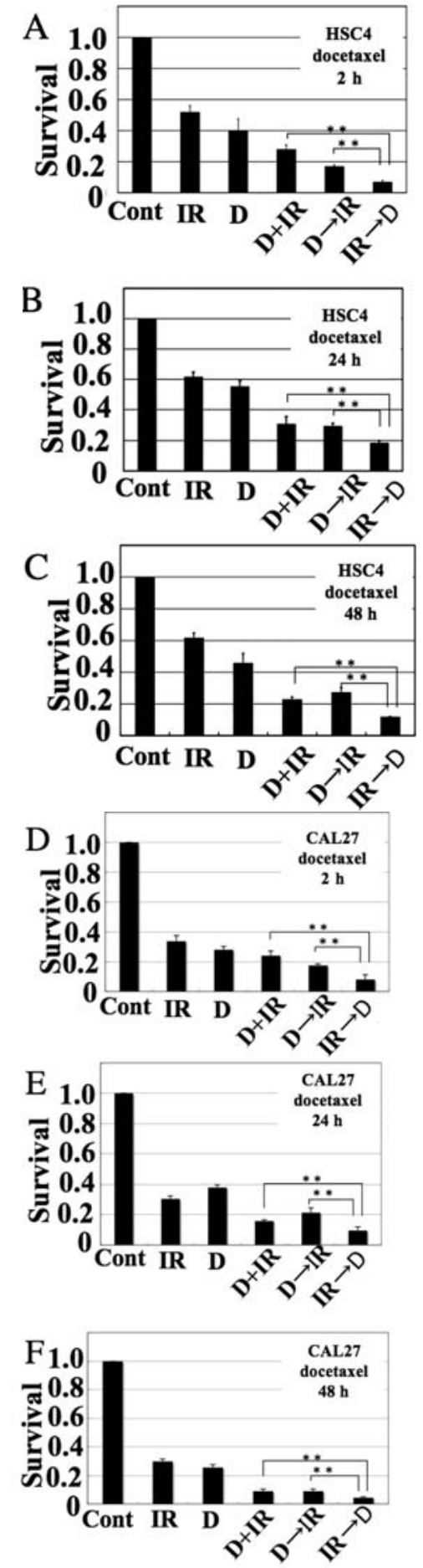

IR: irradiation $3 \mathbf{~ G y}$

$* * p<0.01$

D: docetaxel $10 \mathrm{ng} / \mathrm{ml}(2 \mathrm{~h}), 0.5 \mathrm{ng} / \mathrm{ml}(24,48 \mathrm{~h})$

Figure 3. (A-C) Sensitivity of the HSC4 cells to different schedules of irradiation and docetaxel treatment. Each data point is the mean of three independent experiments. Vertical bars show standard deviations. (D-F) Sensitivity of the CAL27 cells to different schedules of irradiation and docetaxel treatment. Each data point is the mean of three independent experiments. Vertical bars show standard deviations.

was determined by flow cytometry using Cycle Test Plus DNA Regent kit (BD Biosciences, CA, USA), following the manufacturer's protocol. Then, cell cycle was analyzed with a FACScan cytometer (BD Biosciences) using CellQuest ${ }^{\mathrm{TM}}$ and ModFit ${ }^{\mathrm{TM}}$ software.

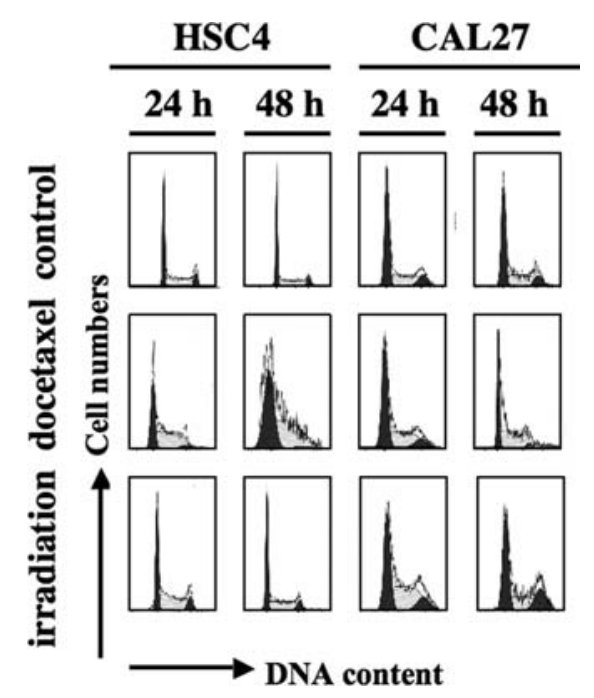

Figure 4. Cell cycle distribution of HSC4 and CAL27 cells after docetaxel treatment or irradiation.

Western blot analysis. To observe the expression of cyclin $\mathrm{B} 1$, retinoblastoma $(\mathrm{Rb})$ and $\mathrm{p} 53$, samples dissolved in sodium dodecyl sulfate polyacrylamide gel electrophoresis (SDSPAGE) buffer without heat treatment were run on $12.5 \%$ SDS-PAGE gels and transferred to polyvinylidine difluoride membranes (Bio-Rad, CA, USA). Anti-human cyclin B1 and human actin antibodies were purchased from Santa Cruz (CA, USA). Anti-human p53 antibody was procured from Medical \& Biological Laboratories Co., Ltd. (Nagoya, Japan). The primary antibody was used in a 1:200 dilution. The secondary peroxidase-conjugated anti-mouse or anti-goat immunoglobulin $\mathrm{G}$ was used in a 1:10,000 dilution. The immunoblots were developed using an ECL system (GE Healthcare UK Ltd., Little Chalfont, UK).

\section{Results}

Cytotoxicity of docetaxel or radiation. The sensitivity of the HSC4 and CAL27 cells to docetaxel or radiation were determined by colony formation assay. CAL27 cells were more sensitive to docetaxel and irradiation than HSC4 cells. After exposure for $48 \mathrm{~h}$, both cell lines showed significantly higher cytotoxicity than in the case of $24 \mathrm{~h}$ exposure. In both cell lines, cytotoxicity increased in a time- and dose-dependent manner after treatment with docetaxel alone. The sensitivity to irradiation was dose-dependent in both cell lines (Fig. 2A-C).

Cytotoxicity of combination treatment. The three schedules of combination treatment are shown in Fig. 1. Treatment doses were determined by the sensitivity of both cell types to docetaxel and irradiation. Doses of docetaxel were determined that gave a survival fraction of $0.4-0.6(10 \mathrm{mg} /$ $\mathrm{ml}$ for $2 \mathrm{~h}, 0.5 \mathrm{ng} / \mathrm{ml}$ for 24 or $48 \mathrm{~h}$ ). An irradiation dose of 3 Gy gave a survival rate of 0.75 in HSC4 cells and 0.5 in CAL27 cells. Schedule C showed a significantly $(\mathrm{P}<0.01)$ higher cell killing rate than schedules $\mathrm{A}$ and $\mathrm{B}$ (Fig. 3A-F).

Cell cycle distribution after treatment with docetaxel and irradiation. All cells accumulated in S-phase 24 and $48 \mathrm{~h}$ 
Table I. Cell cycle distribution of HSC4 and CAL27 cells after docetaxel $(0.5 \mathrm{ng} / \mathrm{ml})$ treatment or irradiation (3 Gy).

\begin{tabular}{|c|c|c|c|c|c|c|}
\hline \multirow{2}{*}{$\begin{array}{l}\text { HSC4 } \\
\text { Treatment/phases }\end{array}$} & \multicolumn{3}{|c|}{$24 \mathrm{~h}$} & \multicolumn{3}{|c|}{$48 \mathrm{~h}$} \\
\hline & G1 & $S$ & $\mathrm{G} 2 / \mathrm{M}$ & G1 & $S$ & $\mathrm{G} 2 / \mathrm{M}$ \\
\hline Control & 43.09 & 45.13 & 11.78 & 56.47 & 36.26 & 7.27 \\
\hline Docetaxel & 39.46 & 57.46 & 3.08 & 48.82 & 49.11 & 2.07 \\
\hline Irradiation & 40.77 & 48.69 & 10.54 & 50.71 & 41.03 & 8.26 \\
\hline \multicolumn{7}{|l|}{ CAL27 } \\
\hline Control & 56.15 & 33.04 & 10.81 & 51.56 & 36.72 & 36.72 \\
\hline Docetaxel & 53.54 & 37.49 & 8.97 & 40.62 & 56.35 & 56.35 \\
\hline Irradiation & 41.74 & 46.82 & 11.44 & 46.64 & 31.46 & 31.46 \\
\hline
\end{tabular}

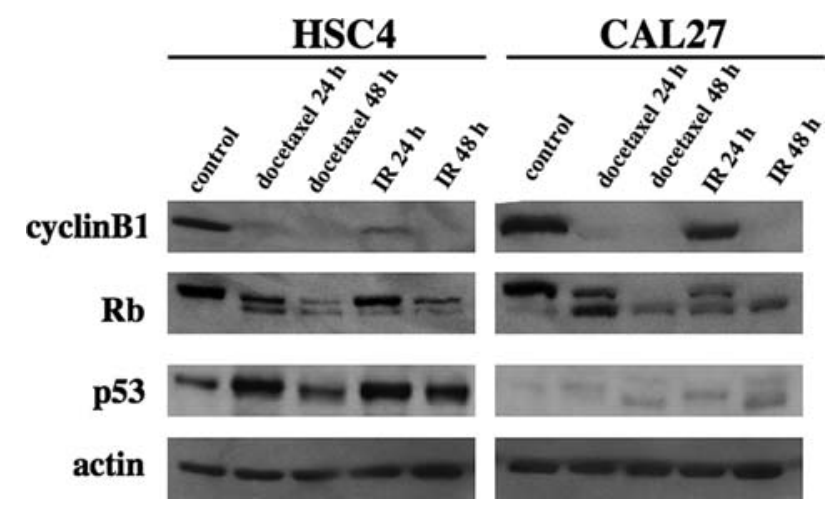

Figure 5. Western blot analysis of HSC4 and CAL27 cells. actin was used as loading control.

after treatment with docetaxel. After irradiation, HSC4 cells showed a slight decrease in G1-phase and an increase in Sphase compared with control. In CAL27 cells, cells in S-phase were increased at $24 \mathrm{~h}$ after irradiation, after that G2/M-phase cells were increased at $48 \mathrm{~h}$ (Fig. 4, Table I).

Protein expression after treatment with docetaxel and irradiation. In order to clarify the mechanism(s) involved in the effects of irradiation and docetaxel on cell cycle distribution, altered protein expression was confirmed using Western blot analysis of Rb, cyclin B1 and p53 after these treatments. A decrease in the level of cyclin B1 was observed at 24 and $48 \mathrm{~h}$ after irradiation and docetaxel treatment. $\mathrm{Rb}$ protein decreased after irradiation or docetaxel treatment. In addition, dephosphorylation was seen, and the total amount of protein was decreased after irradiation or docetaxel treatment. The expression of p53 in HSC4 cells increased after $24 \mathrm{~h}$, but decreased $48 \mathrm{~h}$ after docetaxel exposure (Fig. 5).

\section{Discussion}

The combination of chemotherapy and radiotherapy is used in head and neck cancer treatment, when the chemotherapeutic agent possesses radiosensitizing properties. Such agents reduce the number of clonogenic cells in tumors undergoing radiotherapy by their own cytotoxic action and by rendering tumor cells more susceptible to killing by ionizing radiation $(9,10)$.

In this study, we showed that irradiation pretreatment is more effective than the other treatment schedules in both cell types. Taxanes (docetaxel and paclitaxel) have a radiosensitizing effect (11), but few studies have examined the sequence of taxane and radiation treatment. It has been suggested that taxane treatment leads to the accumulation of cells in G2/Mphase, which is the most radiosensitive phase (12). Docetaxel pretreatment following irradiation showed a higher rate of cell killing in HNSCC cell lines. However, there was no significant difference between pre-radiation and a concurrent chemoradiotherapy schedule in cervical carcinoma cells (13). The present study is the first to show that irradiation pretreatment is the most effective treatment sequence.

Therefore, cell cycle distribution was analyzed after docetaxel treatment or irradiation with flow cytometry to examine the cause of the different results between the three treatment schedules. Previously, G2/M accumulation after docetaxel treatment has been regarded as the mechanism of radiosensitization (14). However, in this study, docetaxel treatment led to accumulation of the cells in S-phase, but not in G2/M-phase. The cytotoxicity of docetaxel pretreatment might be lower than that of radiation pretreatment, docetaxel treatment leads to S-phase accumulation. Furthermore, to clarify cellular status after docetaxel treatment, we examined the changes in expression levels of several proteins that regulate cell cycle progression.

Cyclin B1, a key molecule for G2/M-phase transition during the cell cycle, is overexpressed in various human tumors. The transition from the G2- to the M-phase of the cell cycle requires an accumulation of cyclin B1 and activation of its associated kinase, cdk1 $(15,16)$. Our results indicate that treating HSC4 and CAL27 cells with irradiation and docetaxel resulted in decreased expression of cyclin B1, leading to $\mathrm{G} 2$ arrest. In the present study, the expression of cyclin B1 decreased after irradiation and docetaxel treatment, in comparison with control. These results suggest that cells did not progress to M-phase, which is the most radiosensitive phase, after docetaxel treatment. 
The $\mathrm{Rb}$ gene product is a tumor suppressor that regulates multiple cellular processes, such as growth, differentiation, and apoptosis, and is inactivated by mutations in many types of human cancer. The tumor suppressor activity of $\mathrm{Rb}$ is due to its ability to inhibit cell cycle transition by suppressing the transcription of genes required for G1- to S-phase progression (17). In this study, the decrease in total amount of Rb protein expression and the appearance of dephosphorylation after irradiation or docetaxel treatment suggest that the cell cycle progresses to $\mathrm{S}$ phase.

p53 participates in cell cycle arrest and induces apoptosis in G1/S check point (18). Previously, p53 expression levels have been related to apoptosis following docetaxel treatment in human leukemia cells (19). Whereas p53 mutation status, evaluated either immunohistochemically or by genomic DNA analysis, does not appear to be a promising predictor of response to docetaxel (20). However, both cell types showed a higher cytotoxic effect of irradiation pretreatment than the other treatment schedules, without affecting the state of p53. p53 expression levels were increased at $24 \mathrm{~h}$ after docetaxel treatment and decreased at 48 h. p53 upregulation was shown also after irradiation. Agreement is not provided on mutation of p53 and radiosensitivity (21). Our results concerning interaction p53 status and radiosensitivity did not support this opinion.

In this study, docetaxel pretreatment led to the accumulation of cells in S-phase, which has low radiosensitivity in comparison with other cell cycle phases $(22,23)$. It showed lower cytotoxicity, and we found that irradiation pretreatment is the most effective sequence. In previous studies, cells did not show radiosensitization following docetaxel pretreatment in spite of $\mathrm{G} 2 / \mathrm{M}$ accumulation after docetaxel treatment. In addition, radiosensitization by docetaxel treatment depends on the products of ROS and defects of $\mathrm{GSH}$ regardless of G2/M block (24).

We conclude that irradiation pretreatment significantly enhances docetaxel cytotoxicity through arrest in S-phase in HNSCC cells; therefore this provides the most effective treatment sequence of docetaxel and radiation combination therapy.

\section{References}

1. Caponigro F, Longo F, Perri F and Ionna F: Docetaxel in the management of head and neck cancer. Anticancer Drugs 20: 639-645, 2009.

2. Colevas AD and Posner MR: Docetaxel in head and neck cancer: a review. Am J Clin Oncol 21: 482-486, 1998.

3. Zhao J, Kim JE, Reed E and Li QQ: Molecular mechanism of antitumor activity of taxanes in lung cancer. Int J Oncol 27: 247-256, 2005

4. Hennequin C, Giocanti N and Favaudon V: S-phase specificity of cell killing by docetaxel (Taxotere) in synchronised HeLa cells. Br J Cancer 71: 1194-1198, 1995.
5. Garcia P, Braguer D, Carles G, el Khyari S, Barra Y, de Ines C, Barasoain I and Briand C: Comparative effects of taxol and Taxotere on two different human carcinoma cell lines. Cancer Chemother Pharmacol 34: 335-343, 1994.

6. Ringel I and Horwitz SB: Studies with RP 56976 (taxotere): a semisynthetic analogue of taxol. J Natl Cancer Inst 83: 288-291, 1991.

7. Wakasa T, Inoue T, Kawai N, Murakami J, Kishi K and Fukui K: The combination of ionizing radiation and expression of a wild type p53 gene via recombinant adenovirus induced a prominent tumour suppressing effect in human oral squamous cell carcinoma. Br J Radiol 75: 657-662, 2002.

8. Yip HT, Chopra R, Chakrabarti R, Veena MS, Ramamurthy B, Srivatsan ES and Wang MB: Cisplatin-induced growth arrest of head and neck cancer cells correlates with increased expression of p16 and p53. Arch Otolaryngol Head Neck Surg 132: 317-326, 2006.

9. Kogashiwa Y, Yamauchi K, Nagafuji H, Matsuda T, Tsubosaka T, Tsutsumi T, Karaho T and Kohno N: Concurrent chemoradiotherapy for organ function preservation in advanced patients with hypopharyngeal and laryngeal cancer. Oncol Rep 22: 1163-1167, 2009.

10. Bernier $\mathbf{J}$ and Vrieling $\mathrm{C}$ : Docetaxel in the management of patients with head and neck squamous cell carcinoma. Expert Rev Anticancer Ther 8: 1023-1032, 2008.

11. Hennequin $\mathrm{C}$, Giocanti $\mathrm{N}$ and Favaudon V: Interaction of ionizing radiation with paclitaxel (Taxol) and docetaxel (Taxotere) in HeLa and SQ20B cells. Cancer Res 56: 1842-1850, 1996.

12. Gaglio T, Saredi A and Compton DA: NuMA is required for the organization of microtubules into aster-like mitotic arrays. J Cell Biol 131: 693-708, 1995.

13. Pradier O, Rave-Fränk M, Lehmann J, Lücke E, Boghun O, Hess CF and Schmidberger H: Effects of docetaxel in combination with radiation on human head and neck cancer cells (ZMK-1) and cervical squamous cell carcinoma cells (CaSki). Int J Cancer 91: 840-845, 2001.

14. Liu T, Zhang M, Zhang H, Sun C, Yang X, Deng Y and Ji W: Combined antitumor activity of cucurbitacin B and docetaxel in laryngeal cancer. Eur J Pharmacol 587: 78-84, 2008.

15. Choi EK, Ji IM, Lee SR, Kook YH, Griffin RJ, Lim BU, Kim JS, Lee DS, Song CW, Vorlaufer E and Peters JM: Regulation of the cyclin B degradation system by an inhibitor of mitotic proteolysis. Mol Biol Cell 9: 1817-1831, 1998.

16. Smits VA and Medema RH: Checking out the G(2)/M transition. Biochim Biophys Acta 1519: 1-12, 2001.

17. Giacinti $\mathrm{C}$ and Giordano A: RB and cell cycle progression. Oncogene 25: 5220-5227, 2006.

18. Lu C and El-Deiry WS: Targeting p53 for enhanced radio-and chemosensitivity. Apoptosis 14: 597-606, 2009.

19. Roberts JR, Allison DC, Donehower RC and Rowinsky EK: Development of polyploidization in taxol-resistant human leukemia cells in vitro. Cancer Res 50: 710-716, 1990.

20. Noguchi S: Predictive factors for response to docetaxel in human breast cancers. Cancer Sci 97: 813-820, 2006.

21. Cuddihy AR and Bristow RG: The p53 protein family and radiation sensitivity: Yes or no? Cancer Metastasis Rev 23: 237-257, 2004.

22. Sinclair WK and Morton RA: X-ray sensitivity during the cell generation cycle of cultured Chinese hamster cells. Radiat Res 29: 450-474, 1966

23. Terasima $\mathrm{T}$ and Tolmach LJ: Variations in several response of Hela cells to X-irradiation during the division cycle. Biophys J 3: 11-33, 1963.

24. Geng CX, Zeng ZC, Wang JY, Xuan SY and Lin CM: Docetaxel shows radiosensitization in human hepatocellular carcinoma cells. World J Gastroenterol 11: 2990-2993, 2005. 